\title{
COMPARISON OF THE EFFECTS OF THE CATIONIZATION OF RAW, BIO- AND ALKALI-SCOURED COTTON KNITTED FABRIC WITH DIFFERENT SURFACE CHARGE DENSITY
}

\author{
Stanisław Pruś*, Piotr Kulpiński ${ }^{1}$, Edyta Matyjas-Zgondek ${ }^{1}$ \\ 1 Department of Mechanical Engineering, Informatics and Chemistry of Polymer Materials, Faculty of Material Technologies and Textile Design, \\ Lodz University of Technology, 116 Zeromskiego St. 90-924 Lodz, Poland \\ *Corresponding author. E-mail: rgbcolor@op.pl
}

\begin{abstract}
:
Modification of cotton with 3-chloro-2-hydroxypropyltrimethylammonium chloride (CHPTAC) has been studied extensively and can be operated by means of exhaustion, cold pad-batch, and continuous and pad-steam methods. Most of the research addresses the cationization of cotton fabric after bleaching or mercerization, or during the mercerization process. In our studies, we performed a comparison of the cationization effects on raw, enzymatic, and alkali-scoured cotton knitted fabrics applying CHPTAC according to the exhaustion method. The charge density of the cotton surface was measured using a Muetek Particle Charge Detector and a "back titration" method with polyelectrolytes. These results were compared with the nitrogen content in the samples, K/S measurements of tested samples after dyeing with anionic dye (Acid Yellow 194), and other physicochemical parameters such as weight loss, whiteness, and wettability.
\end{abstract}

\section{Keywords:}

Cotton charge measurement, cationization of cotton, Kjeldahl method, K/S value

\section{Introduction}

In many industries, cationic polysaccharides are replacing the traditional application of cationic polyacrylamides for use as colloid flocculants, due to their lower toxicity and fewer legal restrictions [1]. The cationic functionalization of cellulose is of considerable industrial importance and has been used in the paper industry, cosmetics, textiles, in flotation and drilling fluids [2]. Cationization is the modification of cotton cellulose using quaternary ammonium compounds. In the textile industry, it is an alternative method for achieving better adsorption of chemical compounds and substances, such as dyestuffs, fluorescent whitening agents, and other textile auxiliaries. The cationization of cotton cellulose changes surface electrical charge (electrokinetic potential) by significantly increasing its adsorption properties [3]. Schlack [4] was the first to report the ability of aminated epoxy derivatives to modify cellulose and the first to notice the increased affinity of the modified cellulose toward acid dyes. Champetier and Merle [5] have studied the modification of hydroxylated polymers, including cellulose, by epoxy diethylamine-3-propane followed by an ethyl iodide quaternization to yield ion exchangers. They have also reported the properties of the modified polymers to acid dyes. For many years, different chemical compounds have been studied to achieve the best results of cellulose cationization [6]. In research over the past 20 years, the most frequently studied cationic reagent was 3-chloro-2-hydroxypropyltrimethylammonium chloride (CHPTAC) [6, 7], which has been used in the industry for a long time, and in the cationization of starch among others.
Natural cotton contains approximately $4-12 \%$ of non-cellulosic components, such as hemicellulose, proteins, pectic mater, ash, colorants, waxes, and organic acids, depending on the type, origin, maturity, weathering, and agricultural conditions of raw cotton [8]. The non-cellulosic constituents are mainly located in the outermost layer of the structure, the cuticle, except for the protein residues of the protoplasm and some mineral matter believed to be within the lumen. Although proteins account for the largest portion of the constituents of the cuticle, there is no specific information available on the distribution of nitrogen-containing substances in the cuticle and primary wall [9]. Most of these impurities must be removed by wet preparation procedures involving elevated temperature and long treatment duration before subsequent coloring and finishing operations [8]. For this, in common practice, cottonbased fabrics are subjected to three consecutive steps, namely desizing, scouring, and bleaching [10].

One important step is scouring, in which the complete or partial non-cellulosic components found in cotton are removed alongside impurities, such as machinery and size lubricants [11]. Nowadays, in the textile industry, there are two ways of pretreating cotton, namely, the conventional pretreatment process in alkaline conditions using sodium hydroxide or the implementation of a new, effective alternative to chemical scouring, using enzyme combinations. Conventional cotton pretreatment processes are carried out at $95-100^{\circ} \mathrm{C}$ in alkaline conditions and are mainly based on the reaction between cotton impurities and sodium hydroxide. During the alkali scouring process, the intra- and intermolecular hydrogen bridges of the cellulose are partly cleaved and the polar hydroxyl groups of 
the polysaccharides are solvated [12]. Alkaline pectinase was found to have the optimal bio-scouring process conditions: $\mathrm{pH}$, 8.5; temperature, $55^{\circ} \mathrm{C}$; and incubation time, $90 \mathrm{~min}$. Under these conditions, the amount of pectin removed from the greige cotton fabrics was equivalent to that removed by the scouring and bleaching procedures [13].

Hauser et al. have performed a series of practical works in the field of cotton cationization at the University of North Carolina, USA [14]. Grancaric et al. [13] stated that the fixation of CHPTAC on cellulosic fabrics varies greatly depending on the choice of method, the CHPTAC concentration used, and the amount of alkali, time, temperature, and other parameters. The exhaust method is the least efficient, with typically well under $10 \%$ fixation of used CHPTAC. The pad-batch and pad-steam methods are more effective, with fixation levels at about $25 \%$. The pad-dry-steam method gives about $50 \%$ fixation and the optimized pad-dry-cure yields around $85 \%$. Before increasing the currying temperature, a key in the pad-dry-cure and paddry-steam applications is to remove the water maximally. The modified cotton retains all the beneficial properties of mercerized cotton with a change in surface charge that ensures further quality improvement [13].

Cationization during mercerization with epihalohydrin resulted in novel cotton cellulose. As such, it adds a new dimension to cotton pretreatment and finishing [3]. Published papers describe the dyeing or printing of cationized cotton materials after alkaline or enzymatic pretreatment, bleaching, mercerizing, or directly during the mercerization process [15-20]. The cationization of cotton should be carried out after pretreatment processes such as scouring and bleaching because cationized cotton is more attractive to oxidizing agents, thus contributing to the higher formation of oxycellulose [21].

Numerous studies have aimed to improve the affinity of anionic dyes toward cotton fabric by introducing positively charged sites on cotton [14, 22]. This enables the formation of an electrostatic attraction between the sites and the negatively charged dye molecules, thus eliminating the need for electrolytes in the cotton dyeing process and increasing the dye exhaustion and color yield of the fabric. The use of cationized cotton achieved superior dyeing results without the addition of salt over a short dyeing period. The hydroxyl groups present in glucose units are the main sites of reactive dye fixation and chemical modification [1].

Since 2012, as reported by the Höhenstein Institute of America, ColorZen ${ }^{\circledR}$ cotton coloring has been widely advertised as a new innovative solution [23-30], yielding enormous savings. It was first produced by a specially established LLC ColorZen company in New York. According to corporate information, the company has production facilities located in China, where the technological process of ColorZen ${ }^{\circledR}$ is applied to all raw cotton bales. The cationization of raw cotton fibers (bales) is designed to eliminate unevenness in dyeing since the spinning fibers can be thoroughly mixed. By determining the nitrogen content, it is also possible to define the maximum amount of dye bonding by the fibers to achieve optimum durability. This innovative technology has been certified by the Oeko-Tex organization as
Standard 100, indicating the absence of harmful substances. ColorZen ${ }^{\circledR}$ cotton can be dyed in all available dye systems without additional baskets resulting in fastness properties comparable to those obtained by conventional dyeing. For reactive dyes, ColorZen ${ }^{\circledR}$ technology can reduce dye usage (up to $50 \%)$ due to much higher $(97 \%)$ exhaustion. Moreover, the water can be used in a closed circuit.

In a previous study [31] using the Muetek PCD (Particle Charge Detector) and the "back-titration" method, the authors found that after consecutive stages of pretreatment, the size of the negative charge on the surface of cotton fibers decreased in relation to the size of the charge on raw cotton. In the case of alkaline treatment, the negative charge volume decreased alongside an increase in the amount of $\mathrm{NaOH}$ used, the time, and the temperature of the process. This resulted in the removal of pollutants containing negative charge groups from the surface of the cotton. In the case of enzymatic treatment with alkaline pectinase, the final negative charge was much higher, due to the removal of fewer impurities from the surface of the fibers.

This article aims to study the influence of surface charge in raw, enzymatic, and alkali scoured cotton on the effects of cationization mainly through the estimation of nitrogen content and the properties of cotton dyeing.

\section{Experimental section}

\subsection{Materials and methods}

Raw cotton knitted "single jersey" fabric with a surface weight of $145 \mathrm{~g} / \mathrm{m}^{2}$ was obtained from "MIRWAL" Textile Company, Poland. Tanazym EVO (alkaline pectinase) and Tanaterge Advance (nonionic surfactant) were obtained from Tanatex Poland.

3-chloro-2-hydroxypropyltrimethylammonium chloride (CHPTAC) as $60 \%$ aqueous solution was purchased from Sigma Aldrich. Ready-for-use polyelectrolyte standard solutions, PES-Na (MW $21.800 \mathrm{~g} / \mathrm{mol}$ ) and poly-DADMAC (MW $107.000 \mathrm{~g} / \mathrm{mol}$ ), were purchased from BTG Instruments $A B$ Sweden. C.I. Acid Yellow 194 (Gryfalan Yellow RL commercial quality) was obtained from Boruta-Zachem, Poland. Other reagents were used without further purification.

All scouring (enzymatic and alkaline) and cationization processes were performed using a Redkrome laboratory dyeing machine, model RED P, product of Ugolini, Italy.

\subsection{Enzymatic scouring}

The scouring process for samples of cotton knitted fabrics $(20 \mathrm{~g})$ was started at room temperature in a bath containing $1.5 \mathrm{~g} / \mathrm{l}$ Tanaterge Advance and $0.5 \mathrm{~g} / \mathrm{Na}_{2} \mathrm{CO}_{3}$ at a $1: 15$ liquor ratio. As soon as the bath temperature reached $50^{\circ} \mathrm{C}$ (heating rate $2^{\circ} \mathrm{C} / \mathrm{min}$ ), $1 \%$ owf Tanazym EVO was added. Next, the bath was heated to $60^{\circ} \mathrm{C}$ (rate $2^{\circ} \mathrm{C} / \mathrm{min}$ ), and at this temperature, the scouring process was conducted for $30 \mathrm{~min}$. 
In the next step, 1\% owf ethylenediamine-tetraacetic acid disodium salt (EDTA-2Na) was added to the bath, and the bath temperature was raised to $85^{\circ} \mathrm{C}$ (rate $2^{\circ} \mathrm{C} / \mathrm{min}$ ) for $10 \mathrm{~min}$. After the scouring, the samples were rinsed three times with $300 \mathrm{ml}$ of distilled water at a temperature of $60^{\circ} \mathrm{C}$, followed by cold distilled water to obtain a neutral $\mathrm{pH}$. The samples were dried at ambient temperature.

\subsection{Alkaline scouring}

The alkaline scouring process for samples of cotton knitted fabrics $(20 \mathrm{~g})$ was started at room temperature in a bath containing $1.5 \mathrm{~g} / \mathrm{l}$ Tanaterge Advance and $3 \mathrm{~g} / \mathrm{l} \mathrm{NaOH}$ (4\% owf) at 1:15 liquor ratio. Then, the bath was heated at a rate of $4^{\circ} \mathrm{C} /$ min to $100^{\circ} \mathrm{C}$ temperature and kept for $60 \mathrm{~min}$. For all tests, the process was terminated by cooling the cup contents to $70^{\circ} \mathrm{C}$ at a rate of $4^{\circ} \mathrm{C} / \mathrm{min}$. Next, the samples were rinsed three times with $300 \mathrm{ml}$ of distilled water at a temperature of $70^{\circ} \mathrm{C}$, followed by cold distilled water to obtain a neutral $\mathrm{pH}$. The samples were dried at ambient temperature.

\subsection{Cationization treatment}

Cationization was carried out by the exhaustion method for cotton knitted fabric samples (20 g): raw cotton (R samples), after alkaline scouring (A samples), after enzymatic scouring (B samples), using 1:10 liquor ratio.

After cationization, the samples were rinsed three times with $300 \mathrm{ml}$ of distilled water at a temperature of $60^{\circ} \mathrm{C}$, followed by cold distilled water to obtain a neutral $\mathrm{pH}$. They were then dried at ambient temperature. The temperature course of the cationization process is shown in Figure 1. $\mathrm{NaOH}$ was used as $50 \%$ liquid.

\subsection{Measurement of nitrogen contents}

In our study, the nitrogen content for the cotton knitted fabrics before and after modification was determined by the classical Kjeldahl method in the Institute of Technical Biochemistry, Faculty of Biotechnology and Food Sciences, Technical University of Lodz. Specimens of $1.5 \mathrm{~g}$ cotton knitted fabrics were mineralized in concentrated sulfuric acid with the addition of a selenium mixture in a Büchi K-424/435 apparatus. They were then alkalinized with a concentrated sodium hydroxide solution. The ammonia formed was saturated in a boric acid solution in the Büchi K-314 apparatus. The distillate was titrated with a hydrochloric acid solution against a Tashiro indicator using a Schott Geracle Titronic digital burette to change the color from green to violet.

\subsection{Measurement of the specific charge amount on the cotton knitted fabric surface}

Specimens of $0.25 \mathrm{~g}$ of the tested cotton knitted fabric, cut into approximately $0.5 \times 0.5 \mathrm{~cm}$ pieces, were placed in a $400 \mathrm{ml}$ conical flask, adding $50 \mathrm{ml}$ of $0.0001 \mathrm{~N}$ poly-DADMAC cationic polyelectrolyte, and stirred with a magnetic stirrer for $1 \mathrm{~h}$ at room temperature. As a next step, the fabric pieces were removed, and the solution was filtered to remove all fibers released in the liquid during stirring. An amount equal to $10 \mathrm{ml}$ of filtrate was placed in a measuring cell of the Muetek PCD 03 $\mathrm{pH}$ apparatus, and the piston vibration motion was activated. After stabilization of the potential, the filtrate was titrated with $0.0001 \mathrm{~N}$ PES-Na anionic polyelectrolyte to a stable $0 \mathrm{mV}$ potential. The value of the specific charge was calculated according to the following formula:

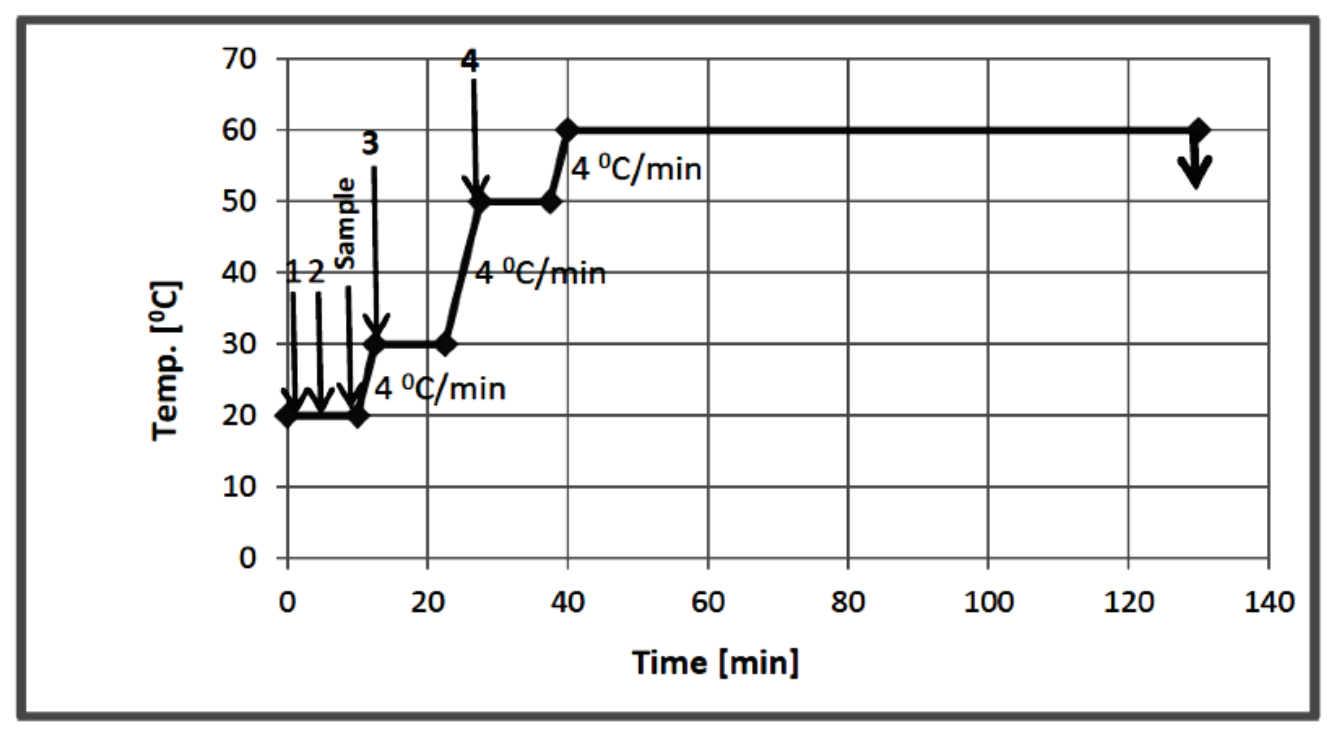

\begin{tabular}{|l|l|l|}
\hline $1-$ Tanaterge Advance & $0.1 \mathrm{~g} / \mathrm{l}$ & $0.1 \mathrm{~g} / \mathrm{l}$ \\
\hline $2-\mathrm{CHPTAC}$ & $4 \%$ owf & $8 \%$ owf \\
\hline $3-\mathrm{NaOH}$ & $1.2 \%$ owf & $2.4 \%$ owf \\
\hline $4-\mathrm{NaOH}$ & $3.95 \%$ owf & $3.95 \%$ owf \\
\hline
\end{tabular}

Figure 1. Cationisation process 


$$
\mathrm{Q}_{\text {surf }}=\frac{\left(\mathrm{V}_{0}-\mathrm{V}_{1}\right) \mathrm{c} \mathrm{V_{ \textrm {c } }}}{\mathrm{m} \mathrm{V}_{\mathrm{a}}}[\mathrm{eq} / \mathrm{g}]
$$

where

$\mathrm{V}_{0}-\mathrm{ml}$ of polyelectrolyte PES-Na for titration of $10 \mathrm{ml}$ polyelectrolyte poly- DADMAC used for cotton knit processing (blind test),

$\mathrm{V}_{1}-\mathrm{ml}$ of polyelectrolyte PES-Na for titration of $10 \mathrm{ml}$ of filtrate after treatment,

C - polyelectrolyte concentration of poly-DADMAC,

$\mathrm{V}_{\mathrm{c}}-\mathrm{ml}$ of polyelectrolyte poly-DADMAC used for treatment,

$\mathrm{V}_{\mathrm{a}}-\mathrm{ml}$ of filtrate used for titration,

$\mathrm{m}$ - test sample weight [g]..

\subsection{Weight loss measurement}

The weight loss of each sample was calculated based on the following equation:

$\Delta \mathrm{W}=\frac{\mathrm{m}_{0}-\mathrm{m}_{1}}{\mathrm{~m}_{0}} \times 100 \%$

where

$\mathrm{m}_{0}$ - weight of the raw sample [g], and

$\mathrm{m}_{1}$ - weight of the sample after treatment [g].

\subsection{Whiteness measurement}

White fabric is that for which the Whiteness Index is in the range of $40<\mathrm{Wl}<(5 \mathrm{Y}-280)$. To assess the shade change of raw, pretreated, and cationized cotton knitted samples, the authors decided to use the word "whiteness" and equation given in the PN ISO 105-J02 standard:

$$
W_{10}=Y_{10}+800\left(0.3138-x_{10}\right)+1700\left(0.3310-y_{10}\right)
$$

where

$\mathrm{Y}_{10}-$ tristimulus value,

$\mathrm{x}_{10}$ and $\mathrm{y}_{10}-$ chromaticity coordinates of the specimen.

In fact, after these processes, there is no specific word and formula to evaluate changes in surface color obtained. Several authors use this word and formula to evaluate such changes in their publications [32-35].

\subsection{Wettability measurement}

For the evaluation of the wettability of cotton knitted samples, the authors decided to use the modified Tegewa Drop Test [36]. Instead of patent blue (anionic dye), methylene blue (cationic dye) was used as a $0.2 \% \mathrm{w} / \mathrm{v}$ water solution. The time lapsed between the contact of a drop of $30 \mathrm{ml}$ of that solution, carefully deposited on the fabric's surface, and its disappearance into the fabric matrix was reported as the fabric wetting time. Images were taken by a Canon SX 410 IS digital camera.

\subsection{Dyeing process and K/S measurements}

To show the influence of the cationization process on the affinity of the cellulose to anionic dyes, the cotton knitted fabric samples were dyed with Gryfalan Yellow RL (C.I. Acid Yellow $194, \lambda_{\max }=460 \mathrm{~nm}$ ) in a bath containing a dye with conc. $2 \%$ owf, at pH 5 for $15 \mathrm{~min}$ at $95^{\circ} \mathrm{C}$, with with liquor ratio 1:50. After dyeing, they were rinsed with hot $\left(70^{\circ} \mathrm{C}\right)$ and tap water until a colorless bath was obtained and were then dried at ambient temperature.

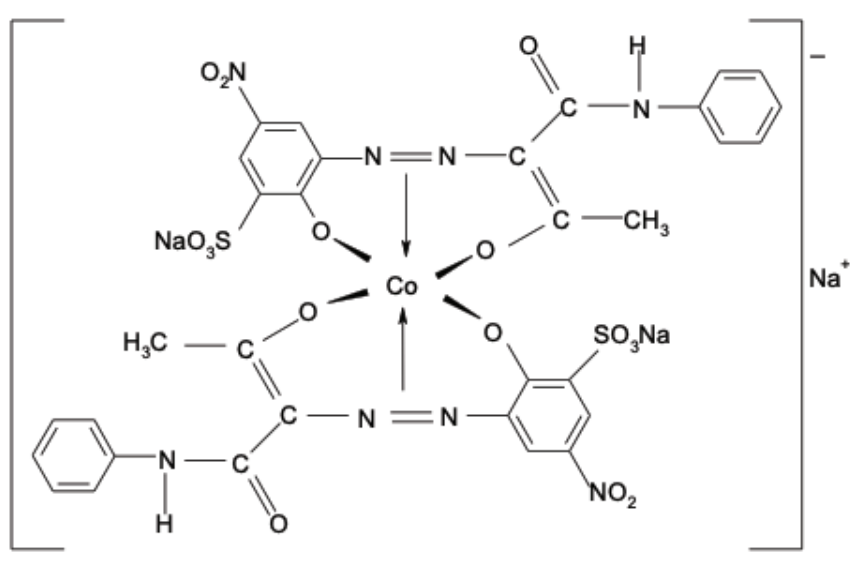

Figure 2. Chemical structure of C.I. Acid Yellow 194.

The concentration of dyes in the case of dyed knitted applications was determined based on the evaluation of colorimetric measurements (light reflected from a white or dyed sample) using a Datacolor 850 spectrophotometer. The results are presented in the form of the dependence $\mathrm{K} / \mathrm{S}$ on the wavelength $f(\lambda)$. The ratio of light absorption coefficient $K$ to the scattering factor $S$ is a simple function of the reflection coefficient from this layer $R_{\infty}$. If the remission factor $R_{\infty}$ is expressed as a percentage, then:

$\mathbf{K} / \mathrm{S}=\left(100-\mathrm{R}_{\infty}\right)^{2} / 200 \mathrm{R}_{\infty}$

where $\mathrm{K}$ is the light absorption coefficient, $\mathrm{S}$ is the light scattering coefficient, and $R_{\infty}$ is the remission factor.

\section{Results and discussion}

The cationization of cellulose with CHPTAC is a twostep reaction mechanism [15] (Figure 3). In the first fast step, the chlorohydrin form of CHPTAC is converted to 2,3-epoxypropyltrimethylammonium chloride (EPTAC) (as shown in reaction I), which subsequently reacts more slowly either with cellulose to form cationized cellulose (as shown in reaction II) or with water to form a hydrolyzed waste material (as shown in reaction III). A reaction could occur between EPTAC and water, which must be avoided as the formed diol is unable to react with cellulose, increasing the cost of the cationic modification [15, 22, 37].

During the cationization process, the degree of substitution is highly influenced by the quantity of base added and the liquor 


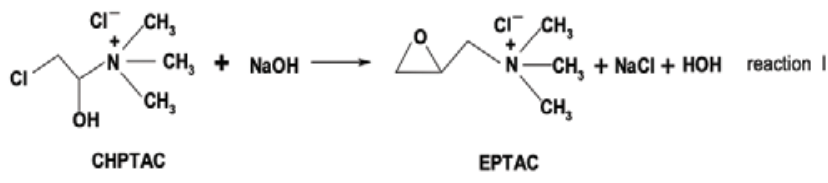<smiles></smiles>

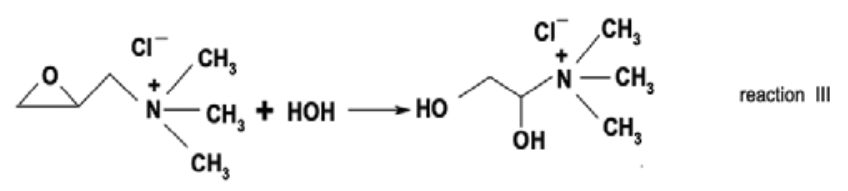

Figure 3. Cationization of cellulose and hydrolysis of EPTAC.

ratio of the bath to the material. The alkali addition is necessary not only to generate EPTAC from CHPTAC but also to weaken the hydrogen bonds between molecules, making cellulose more accessible [38]. Therefore, it can be used as a pretreatment, because an excess of base favors polysaccharide hydrolysis and epoxide degradation toward the aforementioned diol. Besides the hydrolysis of the reactive epoxy system itself, three more directions are also indicated as adverse reactions:

- trimethylamine cleavage reaction (characteristic fishy odor appears) in an alkaline medium and at an elevated temperature from the product of cationization [39, 40],

- ether linkage hydrolysis reaction, similar to reactive vinylosulfon dye linkages with cellulose in a strongly alkaline environment [41], and

- probable, but not described in the literature, possibility of demethylation of a quaternary group in a strongly alkaline environment at the cationization process.

Since no characteristic odor was found, we believe that the first type of reaction did not occur.

The following is a list of sample abbreviations:

Sample R - raw cotton knitted fabric (single jersey) without pretreatment

Sample R4 - cationized sample R at $4 \%$ owf with CHPTAC

Sample R8 - cationized sample R at $8 \%$ owf with CHPTAC

Sample B - bio-scoured sample $\mathrm{R}$ with alkaline pectinase

Sample B4 - cationized sample B at $4 \%$ owf with CHPTAC

Sample B8 - cationized sample B at $8 \%$ owf with CHPTAC

Sample A - alkaline-scoured sample R with sodium hydroxide

Sample A4 - cationized sample A at $4 \%$ owf with CHPTAC
Sample A8 - cationized sample A at $8 \%$ owf with CHPTAC

The obtained results presented in Table 1 were analyzed considering the properties of raw, bio- and alkali- scoured cotton knitted fabrics and specific strongly alkaline conditions of their cationization process. To obtain more reliable results, all experiments were repeated three times, and the data were averaged.

\subsection{Nitrogen content}

Depending on their origin, growing conditions, and degree of maturity, raw cotton fibers that have been identified in their primary wall are $1.1-1.9 \%$ proteins, peptides, and free amino acids. These compounds are the major component of all noncellulosic contaminants. The free amino acids that have been identified in raw cotton are glutamic acid, aspartic acid, valine, serine, threonine [42], proline, and hydroxyproline [43]. Using the standard conversion rate of 6.25 [42] to convert these constituents to nitrogen content, this ranges between 0.176 and $0.304 \%$. Most of the amino acids, low-molecular peptides and proteins were removed with water during the washing process. High-molecular-weight proteins were removed during the alkaline pretreatment process. Depending on the kind of pretreatment, the nitrogen content of scoured fibers is about $0.035 \%$ [42]. After causticized treatment with 10, 20, and $30 \%$ $\mathrm{NaOH}$, the amounts were decreased to $0.0180,0.0171$, and $0.0101 \%$, respectively [44]. In cellulose obtained as a recycled newspaper, it is 0.063 and $0.075 \%$ [45], and for scoured and bleached cotton fabric with an additional $5 \mathrm{~g} / \mathrm{l}$ solution of nonionic detergent (Hostapal CV Clariant) at $95^{\circ} \mathrm{C}$ over a $4 \mathrm{~h}$ treatment, it is $0.00 \%$ [44].

Figure 4 presents the nitrogen content in raw, bio- and alkaline scouring cotton knitted fabrics before and after cationization. According to the results shown in Figure 4, it can be stated that two parallel processes occur during cationization. Proteins containing natural nitrogen are partly removed from the fibers, and, at the same time, nitrogen in the quaternary form is added by the etherification of hydroxyl groups of cellulose. Kjeldahl analysis of nitrogen content in cotton knitted fabrics after cationization reveals the total quantity of nitrogen. Therefore, based on the results of nitrogen content, it is not possible to state in unambiguous terms that the total content of nitrogen found in the cotton after cationization is proportional to the degree of substitution of hydroxyl groups. It was also observed that, as the percentage of cationization increased (except raw cotton), the final content of nitrogen for the samples also increased. $\Delta \mathrm{N}$ in Figure 4 presents the difference in nitrogen content value in the samples before and after the cationization process.

\subsection{Specific charge amount on the cotton knitted fabric surface}

After cationization, changes in negative charge value on the surface of cotton knitted fabrics were observed (Figure 5).

During the cotton cationization process in the presence of sodium hydroxide, two processes occur simultaneously, 
Table 1. Averaged data of all experiments: for specific charge amount $\left(Q_{\text {surf }}\right)$ on the cotton knitted fabric surface, nitrogen content, $K / S$, weight loss $(\Delta \mathrm{W})$, whiteness $(\mathrm{WI})$, and wettability (WET)

\begin{tabular}{|c|c|c|c|c|c|c|c|c|}
\hline Sample & $\mathbf{Q}_{\text {surf }}\left[\mathbf{1 0 ^ { - 6 }} \mathbf{e q} / \mathbf{g}\right]$ & $\mathbf{N}[\%]$ & $\Delta \mathbf{N}[\%]$ & $\mathbf{K} / \mathbf{S}$ & $\left.\Delta \mathbf{K} / \mathbf{S}^{4}\right)[\%]$ & $\Delta \mathbf{W}^{1)}[\%]$ & $\mathbf{W I}$ & $\mathbf{W E T}[\mathbf{s}]$ \\
\hline R & -12.96 & 0.182 & 0 & 1.19 & 0 & 0 & -1.28 & Non wettable $^{2)}$ \\
\hline R4 & -14.16 & 0.135 & -0.047 & 2.11 & 92 & 2.2 & 18.02 & Non wettable $^{2)}$ \\
\hline R8 & -13.2 & 0.1497 & -0.032 & 9.10 & 791 & 2.3 & 28.12 & $600^{3)}$ \\
\hline & & & & & & & & \\
\hline B & -13.74 & 0.122 & 0 & 1.21 & 0 & 3.38 & 24.4 & 5 \\
\hline B4 & -10.52 & 0.1251 & 0.003 & 5.36 & 415 & 3.58 & 30.32 & $12^{3)}$ \\
\hline B8 & -10.47 & 0.147 & 0.025 & 9.80 & 859 & 3.78 & 28.97 & $18^{3)}$ \\
\hline & & & & & & & & \\
\hline A & -7.86 & 0.049 & 0 & 0.53 & 0 & 5.4 & 41.2 & 2 \\
\hline A4 & -6.71 & 0.0687 & 0.0197 & 4.43 & 390 & 5.75 & 48.86 & 4 \\
\hline A8 & -7.11 & 0.118 & 0.069 & 8.12 & 759 & 5.77 & 42.86 & $10^{3)}$ \\
\hline
\end{tabular}

1) $\Delta \mathrm{W}$ was calculated for all samples as a percent weight loss against the weight of the raw sample (R).

${ }^{2)}$ Nonwettable means that after $600 \mathrm{~s}$ the drop of methylene blue water solution deposited on the cotton knitted fabric surface remained as a drop. 3) Penetration means that after a predefined period of time some parts of the drop of methylene blue water solution deposited on the cotton knitted fabric surface were absorbed, while the rest penetrated to the other side of the material and dropped.

$4) \Delta K / S$ - absolute increse $K / S$ for dyed samples, against starting samples (R, B, A)

namely cationization of cellulose and alkaline hydrolysis of some natural cotton impurities. The hydrolysis products at alkaline conditions and elevated temperature form soluble sodium salts and are removed from the cotton surface. Because the cationization process is carried out at a lower temperature than in the pretreatment processes, it results in the incomplete hydrolysis of impurities and a lower degree of their removal. This is particularly evident for the R4 and R8 samples, obtained after the cationization of raw cotton, which contain mainly products of saponification fats, waxes, and pectins. The presence of impurities increases the negative charge value on their surface. It is most likely that due to the high concentration of sodium hydroxide and the high $\mathrm{pH}$ of the bath under the conditions of the cationization process for the A8 sample, the impurities in the deeper amorphous layers of cellulose are further reduced by their hydrolysis to produce products with the acidic group. This causes a slight increase in the negative charge in the fiber compared to the A4 sample, for which the same type of impurities can also be removed during the cationization process, but to a lesser extent.

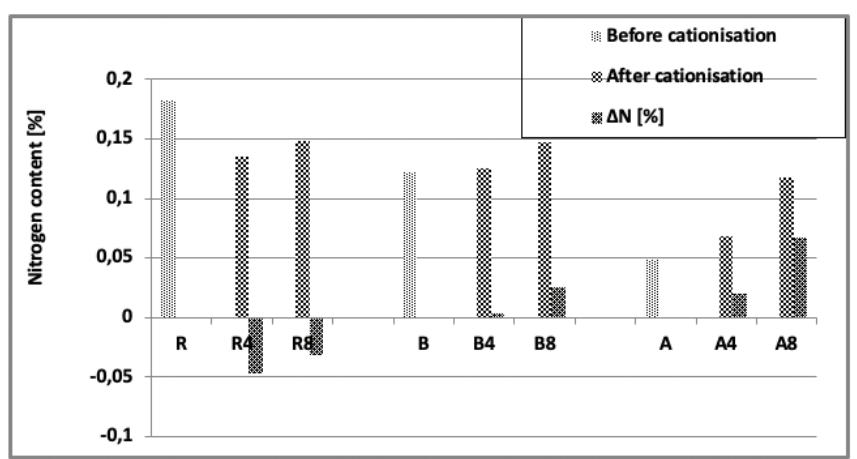

Figure 4. Nitrogen content in knitted cotton fabric samples.
For samples B4 and B8 (enzymatic pretreated), the hydrolyzed impurities (i.e., the products of pectin deestrification and degradation) are removed from cotton as a soluble sodium salt in alkaline conditions during cationization. For these reasons, the negative charge on the cotton surface decreased. Such large variations, in the size of the negative charge on the cotton surface after cationization, are the result of differences in the pretreatment of the tested samples.

\section{3. $\mathrm{K} / \mathrm{S}$ values}

The sorption properties of the cellulosic fibers are significantly influenced by the amount and availability of accessible groups. Thanks to this, it is possible to dye them physically or chemically. Most dyes used in cellulose fibers in the sorption step of the dyeing process are anionic, similar to cellulose. Due to the repulsion between the dye and the fiber, the substantivity of the dye to the fiber is reduced, and the final yield of the sorption is not satisfactory. Cationization modifies the cellulose eliminating such problems. The quaternary ammonium groups with positive charge chemically bonded with the cellulose chain

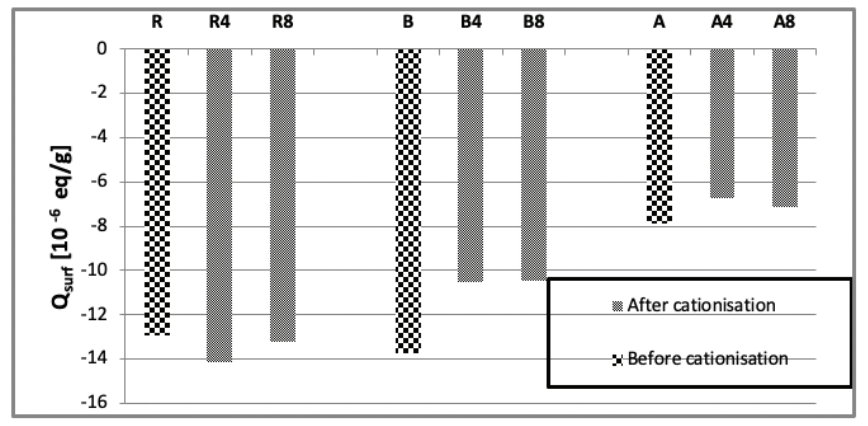

Figure 5. Specific negative charge size on the surface of cotton knitted fabrics: raw, after enzymatic and alkali scouring, before and after cationization treatment. 
are attractive to the negatively charged dyes. After modification by cationization, cotton fiber properties more or less are similar to protein fibers, and they can be dyed even with typical acid dyes.

C.I. Acid Yellow 194 (Figure 2) is a metal-complex 1:2 dye, which is generally recommended for dyeing polyamide and wool fibers in weak acid bath conditions. This compound, as a typical anionic dye, can also bind to cationized cotton fibers in a slightly weak acid bath. In this case, a strong ionic bond between the anionic sulfonic group of the dye and the quaternary ammonium group is formed. In the same manner, Acid Yellow 194 can also dye protein impurities in the cotton fibers, which are not fully removed during the pretreatment process. According to our experience, non-cationized bleached and mercerized cotton cannot be dyed with Acid Yellow 194 [unpublished works].

Table 1 and Figure 6 present the spectral curves K/S for the knitted cotton fabric samples dyed with C.I. Acid Yellow 194 as a result of the difference $\mathrm{K} / \mathrm{S}$ before and $\mathrm{K} / \mathrm{S}$ after dyeing according to the equation:

$\mathrm{K} / \mathrm{S}=(\mathrm{K} / \mathrm{S})_{\mathrm{d}}-(\mathrm{K} / \mathrm{S})_{\mathrm{bd}}$

where

$(\mathrm{K} / \mathrm{S})_{d}$ - value for the sample after dyeing,

$(\mathrm{K} / \mathrm{S})_{\mathrm{bd}}$ - value for the sample before dyeing.

It is observed that for the non-cationized samples (reference samples) dyed with the anionic dye, color intensity was relatively low compared to the samples dyed after cationization. Their K/S value was in the following order due to the increased removal of natural nitrogen impurities: raw, bio-scoured, and alkali-scoured cotton. This may be connected with the binding of C.I. Acid Yellow 194 with only a few proteins (probably with different molecular weights) $[42,43]$ existing as remaining impurities in cellulosic materials after pretreatment. These proteins can bind via ionic bonds with a large anion molecule of the C.I. Acid Yellow 194. It seems that the intensity of dyeing (K/S value) depends on the content of protein impurities. As

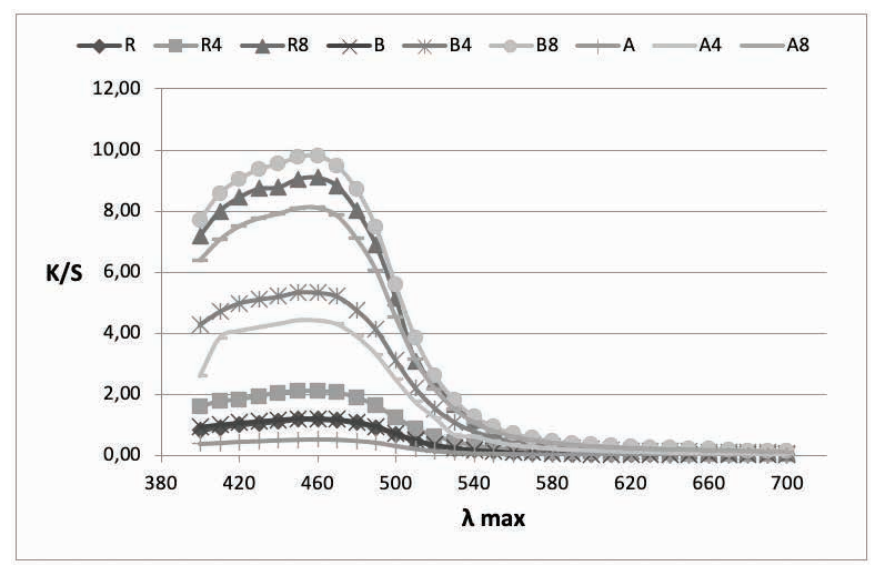

Figure 6. K/S graphs of dyed cotton knitted fabrics in spectral curves. expected, all cationized samples have a much higher $\mathrm{K} / \mathrm{S}$ value than the reference ones.

The measured K/S values do not correspond fully to the total nitrogen content in the samples after cationization. This means that the evaluation of the quantity of nitrogen in cationized cotton fabric samples does not correspond to the content of nitrogen introduced with the quaternary group. This is especially evident for raw cotton and not fully cleaned bio-scoured cotton fabric. Comparing $\Delta K / S$ for $R 8, B 8, A 8, B 4$, and $A 4$, it is observed that the cationization of cotton samples in the exhaustion process is similar between the available hydroxyl groups in cotton fibers and CHPTAC in the same conditions. The final results are not comparable only in the case of R4, probably due to the high amount of impurities consumed by sodium hydroxide during cationization.

According to the obtained results, a higher degree of cationization of cellulose fibers with CHPTAC was obtained for materials with higher negative charge values on the cotton surface. This was confirmed by dyeing with C.I. Acid Yellow 194 and measuring its K/S value. It seems that negative groups located on the cotton fiber surface in acid conditions do not disturb dyeing with anionic C.I. Acid Yellow 194, as the main dyeing mechanism, occurs via ionic bonds between the quaternary ammonium group of cotton and the anionic groups of the dye.

\subsection{Weight loss}

Figure 9 presents the summary results of weight loss for all cotton knitted fabrics during the pretreatment alkaline or bioscouring process and alkaline cationization process compared to the weight of the raw cotton sample.

Cationization also leads to the additional removal of natural impurities. For raw cotton samples cationized on 4 and $8 \%$ owf with CHPTAC, maximal weight loss was observed. For the rest of the trials, weight loss is on a similar level. The lower weight loss for sample B4 seems to be the result of the higher consumption of sodium hydroxide for the creation of sodium salts and the soluble impurities contained in cotton after the bio-scouring process.

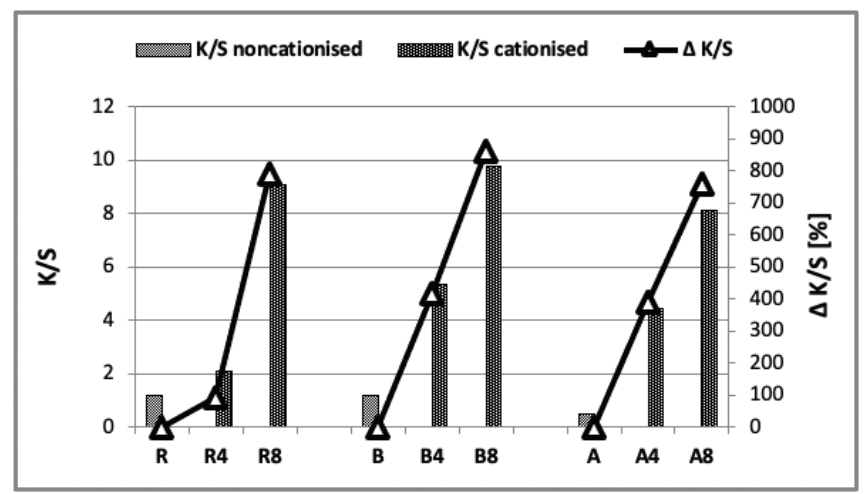

Figure 7. Change in K/S strength for dyed noncationized and cationized samples. 


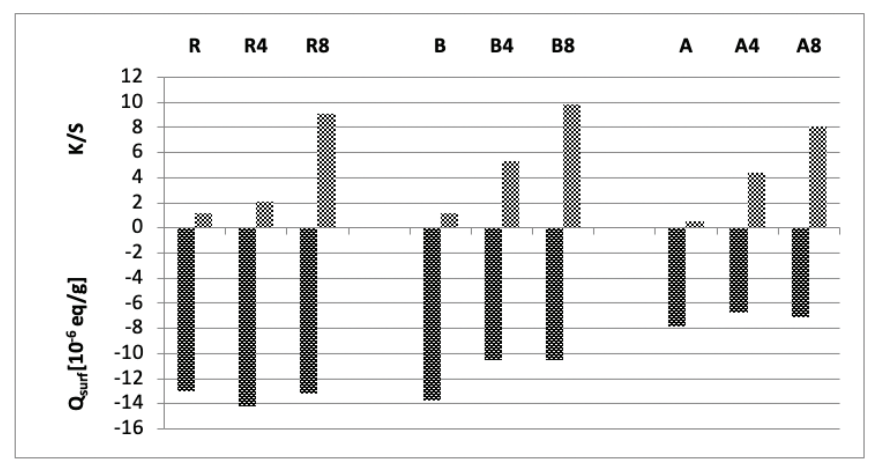

Figure 8. The relation between $\mathrm{K} / \mathrm{S}$ strength and negative size charge on cotton knitted samples surface.

\subsection{Whiteness}

It was observed that after each individual treatment process (enzymatic scouring, alkali scouring, and cationization), the color of the cotton knitted fabric surface compared to the original samples was changed. The largest shade change occurred on the surface of the cationized raw cotton knitted samples, which was in line with expectations.

According to Figure 10, cationization of cotton knitted fabrics on $4 \%$ owf with CHPTAC leads to increasing whiteness due to the treatment of cellulose in alkaline conditions. Together with increasing cationization, a deterioration of whiteness effect on cotton was observed as a result of introducing more quaternary ammonium groups to the cellulose chain.

\subsection{Wettability}

The results presented in Table 2 show that the wettability of cationized bio- and alkali scoured cotton knitted samples decreased compared with the starter samples. During cationization, the available quantity of the hydroxyl groups, which are mainly responsible for wettability, was reduced by etherification. It is observed that cationized samples have decreased wettability. Improved wettability was observed only in the case of raw cotton knitted fabric due to the increased purification of the fibers in alkaline conditions during cationization.

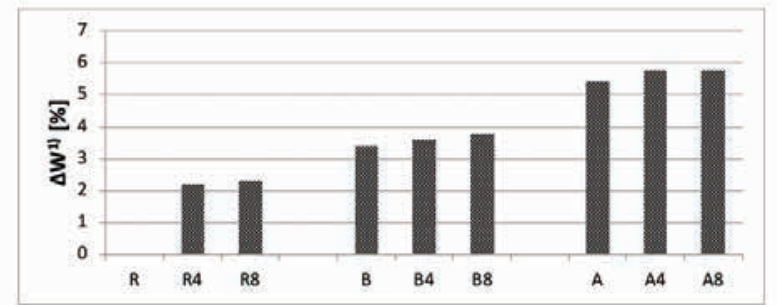

$\Delta W^{1)}[\%]$ - was calculated for all samples as a per cent weight loss against the weight of the raw sample (R)

Figure 9. Change in weight loss in cotton knitted samples after cationization.

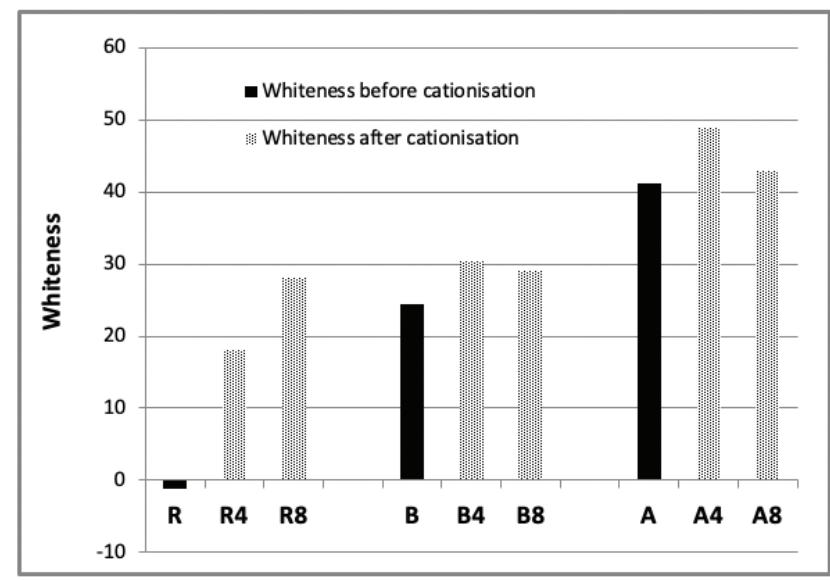

Figure 10. Change in whiteness in cotton knitted samples after cationization.

\section{Conclusions}

The obtained results of the tests confirmed the assumptions that cationization with CHPTAC/EPTAC under the same conditions for cotton knitted fabrics with different levels of pretreatment does not lead to obtaining materials with compatible parameters. At that stage, it was difficult to state that there was a specific relation between sodium hydroxide and CHPTAC and the impurities present in the cotton at each step of pretreatment. The bio- and alkali scouring processes created different negative surface charge values. CHPTAC, as a small molecule, is not substantive to cellulose, but the quaternary group can create ionic bonds with an anionic carboxyl group present in the cellulose and its impurities. These could probably be of help in increasing cationization. It was found that measuring the K/S value for dyed samples

Table 2. Changes in wettability of raw, bio- and alkali-scouring cotton knitted fabrics before and after cationization

\begin{tabular}{|c|c|c|c|c|c|c|c|c|c|}
\hline Sample & $\mathbf{R}$ & R4 & R8 & B & B4 & B8 & A & A4 & A8 \\
\hline \multirow{2}{*}{$\begin{array}{l}\text { Wett- } \\
\text { ability } \\
{[\mathrm{s}]}\end{array}$} & 0 & & & & & & & & \\
\hline & $\begin{array}{c}\text { Non } \\
\text { wettable }{ }^{1)}\end{array}$ & $\begin{array}{c}\text { Non } \\
\text { wettable }^{1)}\end{array}$ & $\begin{array}{c}600 \\
\text { Penetra- } \\
\text { tion }^{2)}\end{array}$ & 5 & $\begin{array}{c}12 \\
\text { Penetra- } \\
\text { tion }^{2)}\end{array}$ & $\begin{array}{c}18 \\
\text { Penetra- } \\
\text { tion }^{2)}\end{array}$ & 2 & 4 & $\begin{array}{c}10 \\
\text { Penetra- } \\
\text { tion }^{2)}\end{array}$ \\
\hline
\end{tabular}

${ }^{1)}$ Non-wettable means that after $600 \mathrm{~s}$, the drop of methylene blue water solution on the cotton knitted fabric surface remained as a drop. 2) Penetration means that after a predefined period of time, some parts of the drop of methylene blue water solution deposited on the cotton knitted fabric surface were absorbed, while the rest permeated to the other side of the material and dropped. 
of cotton with anionic dye was the optimal indicator for the evaluation of the degree of cationization, especially of $\Delta K / S$ measured as the difference of K/S for samples dyed after and before cationization.

The total nitrogen content determined by Kjeldahl analysis in the cotton samples after cationization is the amount of the nitrogen introduced in the cationization reaction and the nitrogen contained in protein impurities that are not removed.

Additionally, we arrived at the following conclusions:

- after cationization, "whiteness" will deteriorate,

- cationization does not significantly affect the charge on the surface of the cotton knitted fabric. The negative charge reduction is related to additional treatment in alkaline conditions and is confirmed as an increase in fabric weight loss,

- after cationization, wettability decreases, and

- cationized cotton can be dyed effectively in a slightly weak acid bath with an anionic 1:2 metal-complex dye containing the sulfonic groups.

\section{References}

[1] Acharya, S., Abidi, N., Rajbhandari, R., Meulewaeter, F. (2014). Chemical cationisation of cotton fabric for improved dye uptake. Cellulose, 21, 4693-4706, doi: 10.1007/ s10570-014-0457-2.

[2] Pal, S., Mal, D., Singh, R. P. (2005). Cationic Starch: An Effective Floculating Agent. Carbohydrate Polymers, 59(4), 517-423.

[3] Tarbuk, A., Grancaric, A. M., Leskovac, M. (2014). Novel Cotton Cellulose by Cationisation During Mercerisation Process - Part 1: Chemical and Morphological Changes. Cellulose, 21(3), 2167-2179, doi: 10.1007/s10570-0140245-z.

[4] Schlack, P. (1938). US Pat. 2.131.120, September 27.

[5] Chavan, R. B., Chattopadhyay, D. P. (1998). Cationisation of cotton for improved dyeability. Colorage Annual, 45, 127-133.

[6] Farrell, M. J. (2012). Sustainable Cotton Dyeing. A dissertation Doctor of Philosophy, North Carolina, Web site: http://repository.lib.ncsu.edu/ir/bitstream/1840.16/7452/1/ etd.pdf.

[7] Farrell, M. J. (2007). Color Matching and Utilization of Teegafix High Efficiency Fiber Reactive Dyes in a Production Setting. Master's Thesis, http://repository.lib. ncsu.edu/ir/bitstream/1840.16/974/1/etd.pdf.

[8] Hao, L., Wang, R., Zhang, L, Fang, K., Men, Y., et al. (2014). Utilizing cellulase as a hydrogen peroxide stabilizer to combine the biopolishing and bleaching procedures of cotton cellulose in one bath. Cellulose, 21, 777-789, doi: 10.1007/s10570-013-0130-1.

[9] Li, Y., Hardin, I. R. (1998). Treating cotton with cellulases and pectinases: Effects on cuticle and fiber properties. Textile Research Journal, 68(9), 671-679.

[10] Habeish, A., Ramadan, M. A., Hasem, M., Sadek, B., Abdel-Hady, M. (2013). New development for combined bioscouring and bleaching of cotton-based fabrics. RJTA, 17(1), 94-103.
[11] Asaduzzaman, Miah, M. R., Hossain, F., Li, X., Zakaria, et al. (2006). A study on the effects of pre-treatment in dyeing properties of cotton fabric and impact on the environment. Journal of Textile Science \& Engineering, 65, doi: 10.4172/2165-8064.1000274.

[12] Das, A. (2013). Mechanism of $\mathrm{NaOH}$ action with cotton during scouring process. Web site: http://textilelearner. blogspot.com/2013/04/mechanism-of-naoh-action-withcotton.html.

[13] Tarbuk, A., Grancaric, A. M., Leskovac, M. (2014). Novel cotton cellulose by cationisation during mercerisation process - part 2: the interface phenomena. Cellulose, 21(3), 2089-2099.

[14] Hauser, P., Slopek, R. P. (2005). Energy, water, and polution reduction with fiber reactive dyes and cationised cotton. Colourage Annual, 52(9), 61-66.

[15] Hasem, M., Hauser, P., Smith, B. (2003). Reaction efficiency for cellulose using 3-chloro-2- hydroxypropyl trimethyl ammonium chloride. Textile Research Journal, Nov 73, 11; Pro-Quest pp. 1017.

[16] Chattopadhyay, D. P. (2001). Cationisation of cotton for low-salt or salt-free dyeing. Indian Journal of Fibre \& Textile Research, 26, 108-115.

[17] Thomason, S. (2007). Optimatization of ionic crosslinking. A thesis submitted to the graduate faculty North Carolina State University. Web site: https://repository.lib.ncsu.edu/ handle/1840.16/2498.

[18] Abbot, A. P., Bell, T. J., Handa, S., Stoddart, B. (2006). Cationic functionalisation of cellulose using a choline based ionic liquid analogue. First published as an Advance Article on the web 4th July, doi: 10.1039/b605258d.

[19] Hall, D. M. et al. (1992). USP 5,330,541; Method for salt free dyeing.

[20] Hashem, M., El-Bisi, M., Sharaf, S., Refaie, R. (2010). Precationisation of cotton fabrics. Carbohydrate Polymers, 79, 533-540, doi: 0.1016/j.carbpol.2009.08.038.

[21] Sonali, M. (2017). Capping and characterizing dyeing properties of cationised cotton. A thesis submitted to the graduate faculty North Carolina State University. Web site: https://repository.lib.ncsu.edu/bitstream/ handle/1840.20/34864/etd.pdf?sequence=1\&isAllowed=y.

[22] Tutak, M., Ozdemir, A. O. (2011). Reactive dyeing of cationised cotton: Effects on the dyeing yields and the fastness properties. Journal of Applied Polymer Science, 119, 500-504, doi: 10.1002/app.32648.

[23] Leonard, T. (2013). Treatment of fibers for improved dyeability. Web site: https://patents.justia.com/ patent/9745694.

[24] Ecosalon (2012). Web site: http://www.ecosalon.com/ interview-michael-harari-on-drying-off-the-textile-dyeingindustry.

[25] Kent, J. J. (2015). Method and apparatus for pre-treatment of non continuous textiles. Web site: https://patents.justia. com/patent/10094066.

[26] ColorZen ${ }^{\circledR}$ - Environmentally friendly solution to cotton dyeing. (2017). Web site: https://www.colorzen.com/.

[27] Our Company - ColorZen ${ }^{\circledR}$. (2019). Web site: https://www. colorzen.com/our-company/.

[28] ColorZen ${ }^{\circledast}$ the Power of Less. (2012). Web site: http:// www.flainox.com/blog/2012/10/colorzen\%E2\%84\%A2technology/. 
[29] How it works/the benefit. (2019). Web site: http://www. colorzen.com/fags.

[30] Hasanbeigi, A. (2013). Alternative and emerging technologies for an energy-efficient, water-efficient, and low-pollution textile industry. Web site: https://www.osti. gov/servlets/purl/1164900.

[31] Prus, S., Kulpiński, P., Matyjas-Zgondek, E. (2019). Changes in the specific charge amount on the surface of cotton fibres during the alkali pre-treatment process. Fibres \&Textiles in Eastern Europe, 27 4(136), 30-37. doi: 10.5604/01.3001.0013.1817.

[32] Hebeish, A., Hasem, M., Shaker, N., Ramadan, M., Sadek, B., et al. (2009). New development for combined bioscouring and bleaching of cotton-based fabrics. Carbohydrate Polymers, 78, 961-972.

[33] Spicka, N., Travcer, P. F. (2013). Complete enzymatic pre-treatment of cotton fabric with incorporated bleach activator. Textile Research Journal, 83, 566-573.

[34] Wijapala Samudrika, U. G., Sharmasena, D. K. A., Bandra, D. M. N., Chaturanga, M. A. I., Rajapaskshe, K.S. (2013). Development of the new scouring methodology for the textile industry. National Engineering Conference, 19th ERU Symposium, Faculty of Engineering University of Moratuva, Sri Lanka. Web site: https://www.mrt.ac.Ik/web/ sites/default/files/eru/files/eru201307.pdf.

[35] Raja, A. S. M., Arputharaj, A., Saxena S., Patil, P. G. (2017). Single bath enzymatic scouring and bleaching process for preparation of absorbent cotton. Indian Journal of Fibre \& Textile Research. 42, 202-208. Web site: http://nopr. niscair.res.in/bitstream/123456789/42058/1/IJFTR\%20 42\%282\%29\%20202-208.pdf.

[36] Tegewa Drop Test. (1987). Melliand Textilberichte. 68, 581-583.

[37] Ghandhi, K. (2014). Cationisation of cotton fabrics, salt free dyeing \& pigment dyeing by exhaust. Web site: http:// www. slidesearchengine.com/slide/cationisation-of-cottonfabrics.
[38] Karnik, P. P. (2002). Use of cationised cotton for textile effluency color. Doctoral Thesis. North Carolina University State. Web site: https://repository.lib.ncsu.edu/bitstream/ handle/1840.16/2856/etd.pdf? sequence=1.

[39] Farrell, M. J., Ormond, R. B., Gabler, W. J. (2015). Quantitative analysis of trime-thylamine in cotton fabrics cationised with 3-chloro-2-hydroxypropyltrimethylammonium chloride. Cellulose. 22, 3435-3439, doi: 10.1007/s10570-015-0692-1).

[40] Odabas, N., Amer, H., Henniges, U., Potthast, A., Rosenau, T. (2017). A comparison of methods to quantify cationisation of cellulosic pulps. Journal of Wood Chemistry and Technology 37, 136-147, doi: 10.1080/02773813.2016.1253100

[41] Gao, Y., Li, Q., Cha, R. (2016). Preparation and application of cationic modified cellulose fibrils as a papermaking additive. International Journal of Polymer Science, doi: 10.1155/2016/6978434.

[42] Taylor \& Francis Group LLC. (2006). Chemical composition of cotton. doi: 10.1201/9781420015270.

[43] Agrawal, P. B., Rogalla, H. (2005). Cotton fibre structure and composition in relation to enzymatic scouring process (Vol. Doctor). Web site: https://ris. utwente.nl/ws/portalfiles/ portal/6070593/thesis_Agrawal.pdf.

[44] Kamel, M. M., El Zawahry, M. M., Ahmed, N. S. E., Abdelghaffar, F. (2009). Ultrasonic dyeing of cationized cotton fabric with natural dye. Part 1: Cationisation of cotton using solfix E. Ultrasonic Sonochemistry, 16, 243249, doi: 10.1016/j.ultsonch.2008.08.001.

[45] Wang, W. (2005). A study on the adsorption properties of quaternized cellulose. Doctoral Thesis. Auburn, Alabama December 16, Web site: https://etd.auburn.edu/bitstream/ handle/10415/829/WANG_WEIJUN_40.pdf? sequence=1. 